\title{
SHORT COMMUNICATION \\ HIGH PARTICIPATION RATE IN MAMMOGRAPHY SCREENING: EXPERIENCE FROM CROATIA
}

\author{
Zrinka Puharić1, Mirna Žulec ${ }^{1}$, Ivana Ceronja ${ }^{2}$, Andrea Šupe Parun ${ }^{3}$ \\ 'Study of Nursing, Technical College in Bjelovar, Bjelovar, Croatia \\ ${ }^{2}$ Croatian Health Insurance Fund, Zagreb, Croatia \\ ${ }^{3}$ Croatian Institute of Public Health, Zagreb, Croatia
}

\section{SUMMARY}

Objective: The aim of the study was to analyse the results of three cycles of mammography screening (MS) in the Croatian National Programme (CNP) for Early Breast Cancer Detection for women aged 50-69 years in the Bjelovar-Bilogora County (BBC) from 2006-2014.

Methods: Data on women aged 50-69 screened during a 9-year period were obtained from the Croatian Cancer Registry and Institute of Public Health reports. Participation rate and performance indicators were examined.

Results: The total of 57,428 women were invited to mammography screening in BBC during a 9-year period and 31,402 mammograms in total were performed. The response rate of $84 \%$ in BBC was consistently higher than the national average of about $60 \%$ reported in 2007, 2013 and 2014.

Conclusion: The National Programme in BBC has been carried out continuously for nine years with a higher response rate compared with the national average, as a result of additional efforts of the Croatian Institute of Public Health team, as well as good cooperation among all programme stakeholders. It was concluded that to achieve better results in the response of women to screening and consequently reduced mortality from breast cancer is possible through tailored health promotion activities.

Key words: mammography screening, breast cancer, participation rate

Address for correspondence: Z. Puharić, Study of Nursing, Technical College in Bjelovar, Trg Eugena Kvaternika 4, 43000 Bjelovar, Croatia. E-mail: zpuharic@vtsbj.hr

https://doi.org/10.21101/cejph.a4684

\section{INTRODUCTION}

Breast cancer (BC) is the most frequently diagnosed neoplasm in women in the countries of the European Union (EU-27) (1).

In 2012, incidence of breast cancer in Croatia was 83/100,000; 2,228 new cases were diagnosed, and mortality was 25/100,000 (994 women died from BC) (2).

Resolution on Cancer Prevention and Control adopted by the World Health Organization points to the need of developing and implementing national programmes of cancer detection. In 2003, the European Council recommended the implementation of cancer screening programmes based on European best-practice guidelines (3).

Key factors for achieving reduced mortality are high coverage of the target population ( $70 \%$ and more), duration of 7-10 years of screening and high-quality implementation of screening (4-6).

Croatia has 21 counties, each county has the Institute of Public Health (IPH). Primary health care level consists of family physician team and community nurses. They provide polyvalent type of care, each for 5,000 inhabitants and have bachelor degree. The Bjelovar-Bilogora County $(\mathrm{BBC})$ is in central Croatia, with 130,000 inhabitants, and belongs to poorer counties with agriculture as the main economic branch.

\section{MATERIALS AND METHODS}

\section{Data}

The retrospective evaluation used two data sources, the Croatian Cancer Registry and National IPH reports.

\section{Participants}

Target population for $\mathrm{BC}$ screening programme includes all women that match defined criteria based on age (50-69 years) and geographic locations (BBC). Women who have died and those who have moved were excluded.

The invitation package sent to the home address contained $\mathrm{BC}$ informative material, questionnaire and a letter of invitation. Every county IPH has provided a free telephone line for all questions and ambiguities. Appointments were made by public health workers at participant's preferred time, absent participants were called by phone. If they could not be reached by phone, IPH employees and community nurses went to the address to see reasons of not responding. Mammography results were independently blind double read by two radiologists If the reading did not match, the third radiologist was asked to make final reading. 


\section{Performance Indicators}

The rate of carcinoma detection was calculated as the number of carcinoma detected per 1,000 women screened. Participation rate, mammography findings and detected carcinoma cases were analysed by descriptive methods using all monthly reports on the public health team activities. Data were analysed using the software connecting all IPH with the Ministry of Health server. Methodology definitions according to the EU guidelines are presented in Table 1 (3).

\section{RESULTS}

During a 9-year period from 2006-2014, in total 57,428 women were invited to mammography screening and 31,402 mammograms were performed. The first cycle was performed from 2006-2009, the second cycle from early 2010-2011, and the third one from late 2011-2014. The average participation rate for Croatia was $63 \% ; 57 \%$ and $60 \%$ per cycle, respectively $(7,8)$. During the first cycle 6 counties made a satisfactory response greater than $70 \%$, in the second and third cycle 3 counties reached this goal. Results for the 2006-2014 period by counties are presented in Figure 1.

In BBC, a total of 31,402 mammograms have been carried out during the above study period (12,063 in the first cycle, 10,705 in the second cycle and 8,634 in third cycle). The response rate for BBC through all three cycles was $85.7 \%$. The summary of participation rate and performance indicators for BBC are shown in Table 2.

\section{DISCUSSION}

\section{Performance Indicators}

Reducing mortality was defined as the most important goal of the national mammography screening programme. A significant and stable decrease in the incidence of late-stage $\mathrm{BC}$ was observed from the third year of screening onward in Italy, while German scientists expect mortality to decrease 10 years after the beginning of the screening programme $(9,10)$. In Austria, mortality during the 10-year monitoring programme decreased by $26 \%$ (11). Therefore, the cumulative impact of the Croatian National Programme (CNP) on mortality rates is yet to be seen.

\section{Participants}

There is a lot of evidence about factors influencing women's participation on mammography screening (MS) as well as obstacles and facilitators. Barriers can be pain concern, radiation, or

Table 1. Key breast cancer screening performance indicators and their definition

\begin{tabular}{|l|l|}
\hline Performance indicator & Definition \\
\hline Extension by screening programme & $\begin{array}{l}\text { Number of target population within the area with organised screening programme/ Number of population } \\
\text { with corresponding age and gender within the whole country }\end{array}$ \\
\hline Participation rate & Number of women invited and screened in episode/ Number of women invited in episode \\
\hline Recall rate & $\begin{array}{l}\text { Number of women recalled for further assessment as a proportion of all women who had a screening } \\
\text { examination. }\end{array}$ \\
\hline Total population & All women in the targeted age group living in the screening area at any time during an invitation round \\
\hline Not eligible women & Women, who moved from the municipality or died before invitation, already had breast cancer \\
\hline Eligible target population & Total population except not eligible women \\
\hline Invitation round & An administrative interval of dates of 2 years \\
\hline Invited women & All women in the eligible target population \\
\hline
\end{tabular}

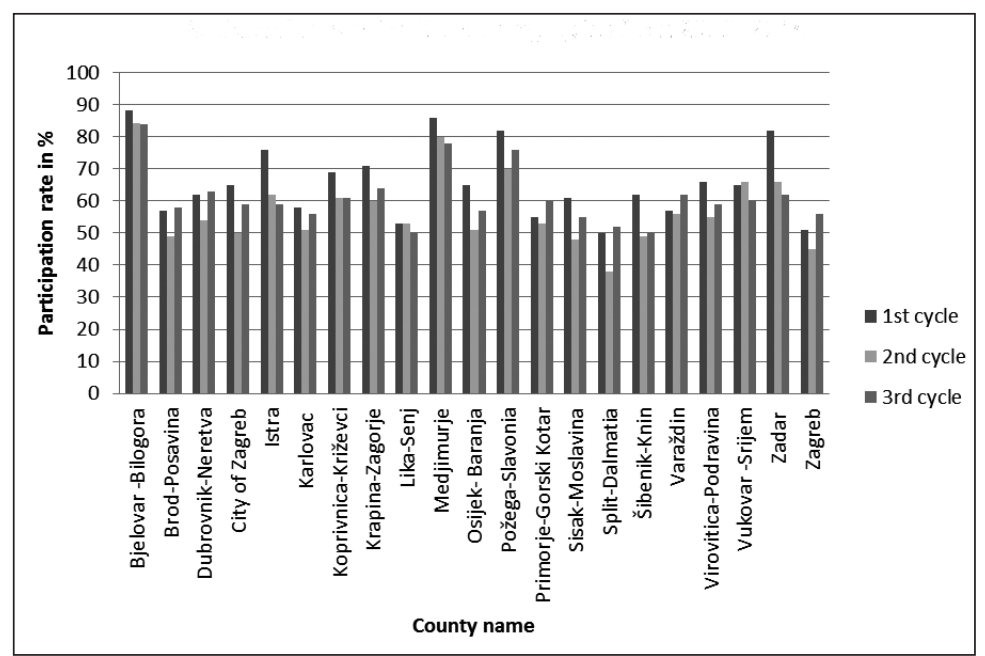

Fig. 1. Participation rate for 3 screening cycles from 2006-2014. 
Table 2. Summary of participation rate and performance indicators for mammography screening in Bjelovar-Bilogora County from 2006-2014

\begin{tabular}{|c|c|c|c|}
\hline & $\begin{array}{c}\text { 1st cycle } \\
2006-2009\end{array}$ & $\begin{array}{l}\text { 2nd cycle } \\
2010-2011\end{array}$ & $\begin{array}{c}\text { 3rd cycle } \\
2012-2014\end{array}$ \\
\hline Total population & 20,675 & 19,010 & 17,743 \\
\hline Died & 863 & 507 & 247 \\
\hline Moved & 3,426 & 3,232 & 2,448 \\
\hline Eligible target population & 16,386 & 15,271 & 12,048 \\
\hline Women screened* & 14,455 & 12,968 & 10,128 \\
\hline Already had breast cancer & 407 & 171 & 111 \\
\hline Done mammography in 1 -year interval & 1,985 & 2,092 & 1,383 \\
\hline Mammograms performed & 12,063 & 10,705 & 8,634 \\
\hline Participation rate & $88.2 \%$ & $84.9 \%$ & $84.1 \%$ \\
\hline
\end{tabular}

${ }^{*}$ Women screened - the total of Already has breast cancer, Done mammography in 1-year interval, and Mammograms performed

embarrassment, being a member of an ethnic minority, low socioeconomic status, perceived inconvenience, and lack of physician referral (12). Facilitators include recommendation from a health care provider, support from a woman's social network, participation in other screening programmes, and perception of risk. Also, recent research found that tailored interventions are relevant for MS attendance (13). There is evidence which supports and classifies different screening promotion interventions in particular groups. Some of the previous research shows that women in urban settings, with higher level of education and employed women have higher levels of knowledge about $\mathrm{BC}$ compared to women living in rural areas, less educated and unemployed women (14, 15). Also, women living alone, single mothers, women with one child or three or more children, and those with low social participation, low control and greater stress, older age women, living temporarily out of the place of residence, as well as those in greater distance from health services may face significant barriers to the use of preventive health care services $(15,16)$.

Considering the above and having in mind that $\mathrm{BBC}$ is the fourth least developed county in Croatia, employees of county IPH decided to make additional efforts to reach high participation rates. For example, the new addresses were checked through family physicians, insurance companies, neighbours, etc. IPH workers obtained information about non-respondent women by telephone to motivate women to respond to the CNP. Free telephone line was available on a daily basis for advice and information.

\section{Family Physicians}

Family physicians can play a big role in educating and supporting women to MS and numbers of activities with them were implemented (17). IPH organized lectures in order to educate them about the details of mammography procedure. Lectures were held on annual basis, to ensure all new physicians in the area were familiarized with the programme and got updated information.

\section{Patient's Associations}

Patient's associations and social interactions have a great influence on high attendance rates (18). IPH therefore closely cooperated with Europe Donna - independent non-profit organisation whose members are affiliated groups from countries throughout Europe. President of the local subsidiary is an IPH employee, who facilitated communication between professionals and non-professionals. Twice a year major national events to raise consciousness about $\mathrm{BC}$ are organized - $\mathrm{BC}$ Awareness Day in October and Daffodil day in February (in 2015 for 19th time). Marking these days is organized also in BBC. During the implementation of these actions, promotional stands are set in busy places in the city where members of the association distribute leaflets on $\mathrm{BC}$, and women can receive additional information. Also, numerous humanitarian actions have been organised around the county like selling flowers or items that were created by members of the association.

\section{Media}

The BBC health workers used local media (newspapers and radio station) to raise awareness about $\mathrm{BC}$. Before each activity mentioned above, a number of articles were published in local newspapers, with positive feedback from women cured for BC. The same was done through radio shows at local radio stations. Precisely, the local media have an important role in raising awareness to attend screening, as women are more likely to connect and identify with someone they know, or with people from the immediate environment.

\section{Obstacles}

In terms of lessons learned, the capacity constraint of the Department of Radiology, Medicine, General Hospital in Bjelovar was occasional problem, and mammography appointments have been delayed at times. The big problem recognized by authors is that no one is responsible for provision of enough mammography terms due to not defined obligations for health institution. Also, providing the readings of mammographic examination within three weeks was not always possible due to the capacity/staffing considerations at the county hospital.

\section{Lessons to Be Learned}

As demonstrated in this paper, the response rate to MS in $\mathrm{BBC}$ was consistently higher than the average national response rate. Nonetheless, future programmes should aim to further 
decrease the number of non-responsive women, by improving the programme implementation in all segments. In particular, introducing systematic quality control and educating the target population about the importance of responding to examinations is recommended. Improvement in all segments of the implementation of these programmes, the introduction of systematic quality control and education of the population about the importance of responding to examinations may result in reduction in mortality rates from BC. In addition, it is possible to improve the quality of life of patients with early and timely diagnosis.

\section{Limitations of the study}

It was not possible to determine whether and in what amount other counties implemented additional ongoing activities to encourage women to participate in the programme (such as media, family physicians, lectures, etc.). Such data would help explain the results of the programme. Also, no other data regarding performance indicators were available due to recent changes of the collecting data software.

\section{CONCLUSION}

Even though the participation rate in the CNP of BC Early Detection in $\mathrm{BBC}$ was above national average, there is still room for improvement. At the national level, the Ministry of Health could bring more attention to media coverage (television, radio, Internet), and should invest additional efforts in continuous education of professionals involved in screening, including family physicians and community nurses. Information about residence addresses, deaths and patients with previous cancer diagnoses should be accurate and regularly updated.

We can conclude that high participation rates are possible only with cooperation of all parts of healthcare partners.

\section{Conflicts of Interests}

None declared

\section{REFERENCES}

1. Ferlay J, Steliarova-Foucher E, Lortet-Tieulent J, Rosso S, Coebergh JW, Comber H, et al. Cancer incidence and mortality patterns in Europe: estimates for 40 countries in 2012. Eur J Cancer. 2013 Apr;49(6):1374403.

2. Ferlay J, Soerjomataram I, Ervik M, Dikshit R, Eser S, Mathers C, et al. GLOBOCAN 2012 v1.0, Cancer Incidence and Mortality Worldwide:
IARC CancerBase No. 11 [Internet]. Lyon: International Agency for Research on Cancer; 2013 [cited 2016Nov 16]. Available from: http:// globocan.iarc.fr.

3. Council Recommendation of 2 December 2003 on cancer screening (2003/878/EC). Off J Eur Union. 2003 Dec 16;46(L327):34-8.

4. Perry N, Broeders M, de Wolf C, Törnberg S, Holland R, von Karsa L, editors. European guidelines for quality assurance in breast cancer screening and diagnosis. 4th ed. Luxembourg: Office for Official Publications of the European Communities; 2006.

5. Gabe R, Duffy SW. Evaluation of service screening mammography in practice: the impact on breast cancer mortality. Ann Oncol. 2005;16 Suppl 2:ii153-62.

6. Džono-Boban A, Čale Mratović M, Mašanović M. Analysis of the results of mammography screening in Dubrovnik-Neretva County 2006-2009. Acta Med Croatica. 2010 Dec;64(5):453-9. (In Croatian.)

7. Epidemiological News: Results of implementation of the National Program for early detection of breast cancer. Zagreb: Croatian Institute of Public Health November; 2015.

8. Croatian National Cancer Registry. Cancer incidence in Croatia 2012. No. 37. Zagreb: Croatian Institute of Public health; 2014.

9. Foca F, Mancini S, Bucchi L, Puliti D, Zappa M, Naldoni C, et al; IMPACT Working Group. Decreasing incidence of late-stage breast cancer after the introduction of organized mammography screening in Italy. Cancer. 2013 Jun 1;119(11):2022-8.

10. Heywang-Koebrunner S, Bock K, Heindel W, Hecht G, Regitz-Jedermann L, Hacker A, et al. Mammography screening - as of 2013. Geburtshilfe Frauenheilkd. 2013 Oct;73(10):1007-16.

11. Oberaigner W, Buchberger W, Frede T, Knapp R, Marth C, Siebert U. Breast cancer incidence and mortality in Tyrol/Austria after fifteen years of opportunistic mammography screening. BMC Public Health. 2010 Feb 20;10:86.

12. Hanson K, Montgomery P, Bakker D, Conlon M. Evaluation of an intervention designed to recruit Canadian women to mammography screening. J Community Health Nurs. 2011 Jul;28(3):130-43.

13. Sohl SJ, Moyer A. Tailored interventions to promote mammography screening: a meta-analytic review. Prev Med. 2007 Oct;45(4):252-61.

14. Legler J, Meissner HI, Coyne C, Breen N, Chollette V, Rimer BK. The effectiveness of interventions to promote mammography among women with historically lower rates of screening. Cancer Epidemiol Biomarkers Prev. 2002 Jan;11(1):59-71.

15. Lagerlund M, Sontrop J, Zackrisson S. Psychosocial factors and attendance at a population-based mammography screening program in a cohort of Swedish women. BMC Womens Health. 2014 Feb 24;14(1):33.

16. Stamenić V, Strnad M. Urban-rural differences in a population-based breast cancer screening program in Croatia. Croat Med J. 2011 Feb;52(1):76-86.

17. François G, Van Roosbroeck S, Hoeck S, Markovskaia E, Van Hal G. A pivotal role for the general practitioner in a mixed mammographic screening model. Rev Epidemiol Sante Publique. 2012 Apr;60(2):150-6.

18. Kaltsa A, Holloway A, Cox K. Factors that influence mammography screening behaviour: a qualitative study of Greek women's experiences. Eur J Oncol Nurs. 2013 Jun;17(3):292-301. 